\title{
A LUTA PELA CONCRETIZAÇÃO DO DIREITO: ANÁLISE DA TRAMITAÇÃO PROCESSUAL DE IDOSOS NA DEFENSORIA PÚBLICA DO PIAUÍ
}

\section{THE STRUGGLE FOR THE REALIZATION OF THE RIGHT: ANALYSIS OF THE PROCEDURE FOR ELDERLY IN THE PIAUÍ STATE PUBLIC DEFENDER'S OFFICE}

\author{
Cecilia Maria Resende Gonçalves de Carvalho* \\ José Augusto Paz Ximenes Furtado** \\ Ana Beatriz Gonçalves de Carvalho***
}

\begin{abstract}
RESUMO: a demora no atendimento à pessoa idosa pode trazer graves consequências e tem sido associada a práticas discriminatórias e preconceituosas. A ação de interdição é um tema de interesse público por ser um mecanismo de amparo e proteção à pessoa interditada. O objetivo desta pesquisa é analisar a garantia da proteção ao direito à prioridade processual em ação de interdição civil envolvendo pessoa idosa. O estudo, de base documental e bibliográfica, utilizou processos judiciais de interdição civil ajuizados no ano de 2013 pelo Núcleo Especializado de Defesa e Atenção ao Idoso e da Pessoa com Deficiência da Defensoria Pública Estadual do Piauí. Dos 71 processos analisados, apenas $25 \%$ das ações de interdição tiveram expedição do termo de curatela definitivo; $59 \%$ não foram julgados e, destes, em apenas 34\% foi concedida a tutela antecipada. Muitos idosos não conseguiram ter, em vida, a solução do seu problema. Os procedimentos adotados na ação de interdição levaram, na maioria dos casos, muito tempo. A vulnerabilidade biológica e social é uma condição vivenciada pelos idosos desta pesquisa, além de um conjunto de dificuldades impostas pelo Judiciário. Espera-se que os resultados dessa investigação possam auxiliar na melhor compreensão do problema e tragam contribuições para o alcance de uma proposta jurídica que atenda, ainda em vida, às necessidades da pessoa idosa. As informações alcançadas sobre o tema poderão estimular outras pesquisas na área, visando à melhoria da qualidade de vida da população pesquisada.
\end{abstract}

PALAVRAS-CHAVE: Acesso à justiça. Ação de interdição. Velhice.

ABSTRACT: The delay in service for the elderly can bring serious consequences and it has been linked to discriminatory and prejudiced practices. The insanity proceeding is a theme of public interest because it is a mechanism to support and protect the interdict. The objective of this research is to analyze the guarantee of protection of the right to procedural priority in insanity proceedings involving elderly people. This study, based on documents and bibliographic sources, made use of

\footnotetext{
* Professora do Departamento de Nutrição e Tutora do Programa de Educação Tutorial da UFPI. E-mail: cecilia.ufpi@hotmail.com

** Graduado em Direito pela Associação de Ensino Unificado do Distrito Federal - AEUDF (1991). Especialista em Direito Processual pela Universidade Federal de Santa Catarina - UFSC (2000). Especialista em Direito Público pelo Centro de Ensino Unificado de Teresina - CEUT (2002). Especialista em Direito Processual pela Universidade Federal do Piauí - UFPI (2002). Mestre em Educação pela Universidade Federal do Piauí - UFPI (2008). Doutorando em Direito Civil pela Universidade de Buenos Aires - UBA. E-mail: augusto.ximenes@hotmail.com

*** Acadêmica do curso de Direito da Faculdade Integral Diferencial - FACID DeVry Brasil. Estagiária da Defensoria Pública do Estado do Piauí, período 2014-2015. E-mail: beatrizcrvalho@hotmail.com
} 
lawsuits of civil interdiction regarding actions filed in 2013 by the Specialized Center for Defense and Care for Elderly and Disabled People of the of the Piauí State Public Defender's Office. From the 71 cases examined, only $25 \%$ of the insanity proceedings had the expedition of the definitive term of curatorship; 59\% have not yet been judged, and, from these, only 34\% had the preliminary injunction grant. Many elderly died before a judicial solution. The procedures adopted for the insanity proceeding, in most cases, have taken too long time. The biological and social vulnerability is a condition lived by the elderly researched, besides a set of difficulties imposed by the judiciary. It is expected that the results of this research will help to better understand the problem and bring intervention models, as legal proposals that contribute to meet the needs of the elderly while they are still alive. The information collected about the subject may stimulate other researches in the area aiming at the improvement in life quality of the studied population.

KEYWORDS: Access to justice. Insanity proceeding. Old age.

\section{INTRODUÇÃO}

O tema velhice e direito é atual e motivador de questionamentos, dado o processo de transição demográfica pelo qual passa o Brasil. De acordo com o Instituto Brasileiro de Geografia e Estatística (IBGE, 2012), o quantitativo da população idosa já alcançou número superior a 20 milhões, representando mais de $10 \%$ da população brasileira, com estimativa de que alcance, em 2060, 26,7\% da população.

As estimativas do Banco Mundial (2011) são de que o País, nos próximos 40 anos, terá uma população idosa crescendo, anualmente, a uma taxa de 3,2\% (sendo que a população total crescerá a uma taxa de 0,3\%), e atingirá 64 milhões de idosos em 2050, o que representará, naquele ano, cerca de $30 \%$ da população total.

Esta mudança demográfica no perfil da população brasileira exige uma nova postura do mundo jurídico, principalmente no âmbito das práticas e procedimentos jurisdicionais. Como diz Beck (1998), vive-se hoje numa sociedade de risco, pois se convive com perigos que transcendem a esfera individual e acometem a sociedade de forma geral, como, por exemplo, os problemas ecológicos, a insegurança econômica, o desemprego estrutural e a instabilidade.

Além da insegurança própria da sociedade de risco, o processo globalizatório também influencia a estrutura dos relacionamentos interpessoais, ao estimular a ditadura do instantâneo, pela dinâmica do tempo curto e da rapidez, em que tudo é, modernamente, líquido (BAUMAN, 2004).

Em resposta a tais questões e na tentativa de conciliar a dinâmica social e a jurídica, o direito recorre a construções técnicas artificiais, a exemplo dos conceitos de "segurança jurídica” ou de "verdade real", e, ainda, na tentativa de acompanhar o tempo da sociedade, cria alquimias, como a antecipação de tutela e acelerações procedimentais, como formas de antecipar o resultado 
processual, que somente seria atingido mediante o provimento jurisdicional final, qual seja, uma sentença de mérito (LOPES JÚNIOR, 2003).

Nessa perspectiva, cumpre salientar que o tempo do direito está completamente desvinculado do tempo da sociedade, celeuma que se torna paradoxal no mundo contemporâneo, que se acostuma com a virtualidade e rapidez das relações sociais e, consequentemente, não se quer esperar pelo processo; daí o surgimento das tutelas antecipadas no âmbito civil e das prisões cautelares na esfera penal.

A percepção da demora processual, na prestação jurisdicional, é objeto de pesquisa e estudo dos mais diversos doutrinadores. Muito se estuda e se preocupa com a efetivação do provimento final quando se tem o tempo como principal inimigo.

Essa questão da demora processual merece novos contornos e a sua relação com o excesso de tempo, na prestação jurisdicional, torna-se mais evidente quando o processo envolve pessoa idosa, que, por si só, merece um tratamento especial e impõe o estabelecimento de direitos peculiares, como a prioridade na tramitação processual e a proteção integral por parte do Estado, da sociedade e da família, nos termos da Constituição Federal de 1988, do Código de Processo Civil e do Estatuto do Idoso. Ademais, sob o enfoque do tempo, é preciso lembrar que o seu valor adquire a dimensão do iniludível quando se chega à velhice.

Por sua vez, a complexidade do tema se acentua ao se escolher, como parâmetro de estudo, a ação de interdição, pois, além de versar acerca do estado da pessoa, demanda incidentalmente, em regra, uma tutela de urgência - qual seja, a antecipação de tutela.

A ação de interdição está prevista tanto no Código Civil quanto no Código de Processo Civil, e possui, como fim último, a proteção daqueles que não mais conseguem ter autonomia para exercerem, por si sós, os atos decorrentes da vida civil. Assim, por meio de um processo judicial, ou seja, pelo processo de interdição, requer-se ao magistrado um provimento jurisdicional declaratório acerca da incapacidade do interditando, que pode ser de incapacidade absoluta ou relativa, conforme preceitua a legislação civilista brasileira.

Por ser uma espécie de ação relativa ao estado da pessoa, pode-se dizer que está, intrinsecamente, relacionada ao princípio da dignidade da pessoa humana, podendo-se até mesmo afirmar que a efetivação de tais demandas, ou seja, a obtenção do termo de curatela nas ações de interdição em tempo hábil, possui uma dimensão da concretização do princípio da dignidade da pessoa humana.

No que tange à pessoa idosa, o tema ainda é pouco discutido no meio acadêmico e há, na sociedade, uma falta de conhecimento do que representam os direitos da pessoa idosa, o que 
dificulta o reconhecimento da existência de benefícios adquiridos por esse segmento populacional. As pesquisas, com ênfase na realidade social da pessoa idosa envolvida em ações judiciais que tramitam na Defensoria Pública do Piauí, são muito pouco realizadas, daí a necessidade de voltar o olhar para o estudo do tema e da sua aplicação em âmbito local.

Nesse sentido, é preciso saber se o poder público tem construído mecanismos concretos para garantir o direito à prioridade processual em favor da pessoa idosa em se tratando de ação de interdição. E como saber se esses direitos, em geral, estão assegurados e respeitados? Será que o direito à concessão de tramitação processual prioritária para a pessoa idosa é efetivado? Existe um trabalho direcionado para evitar que sejam reproduzidas práticas de desrespeito aos direitos da pessoa idosa na condução do processo judicial de interdição?

Assim, o presente trabalho se desenvolveu a partir da análise da garantia da prioridade processual, nas ações de interdição civil envolvendo a pessoa idosa, nos processos ajuizados pelo Núcleo Especializado de Defesa e Atenção ao Idoso e da Pessoa com Deficiência na Defensoria Pública do Estado do Piauí, que, por conta da sua própria natureza jurídica, exigem maior rapidez no trâmite processual.

Para tal desiderato, o escopo específico desta pesquisa é analisar os processos que figuram nas ações de interdição; investigar os aspectos ligados à temporalidade processual destas ações; identificar o tipo de parecer técnico prestado pelos juízes e os argumentos que fundamentam as suas decisões; conhecer os fatores envolvidos no trâmite processual e, ainda, analisar as consequências da demora na tramitação das ações de interdição envolvendo pessoa idosa atendida no âmbito da Defensoria Pública do Estado do Piaú́.

\section{A PESSOA IDOSA E OS SEUS DIREITOS: CONQUISTAS CONSAGRADAS NAS POLÍTICAS BRASILEIRAS}

No Brasil, a partir da Constituição Federal (CF) de 1988 os idosos começaram a ser alvo das Políticas Públicas. No Art. 50 ${ }^{\circ}$ caput, da carta constitucional, foi proclamada a igualdade de todos perante a lei e garantido aos idosos o direito à vida, seguido do direito de liberdade, entre outros. Além disso, no Inciso XXXV, do referido artigo, a doutrina constitucional garante ao idoso recorrer ao Poder Judiciário, na hipótese de qualquer lesão ou ameaça a seu direito (BRASIL, 1988).

No mesmo sentido surgiu, em 1994, a Lei $n^{0}$ 8.842, regulamentada pelo Decreto 1.948/96, que dispõe sobre a Política Nacional do Idoso (PNI) - a primeira política específica aprovada com o 
objetivo de assegurar os direitos sociais dos idosos. É importante frisar que essa lei ainda cria condições de promover a autonomia, a integração e a participação efetiva desse público na sociedade, na perspectiva de estabelecer o compromisso entre o poder público e a sociedade (BRASIL, 1994).

Numa etapa posterior, surge o Estatuto do Idoso, criado pela Lei $\mathrm{n}^{\circ} 10.741$, promulgado em $1^{\text {o }}$ de outubro de 2003, em consonância com o Plano de Ação Internacional sobre o Envelhecimento, firmado em 2002 juntamente com a PNI (BRASIL, 2003). O aludido documento legal representa um grande avanço, no sentido de assegurar o respeito e o cumprimento dos direitos fundamentais estabelecidos na Constituição Brasileira.

A Lei $n^{0} 10.741$ responsabiliza não apenas o Estado, mas toda a sociedade, pela prioridade que deve ser dada aos direitos de seus anciãos. Nesse sentido, o Estatuto do Idoso, no seu Artigo $3^{\circ}$, preconiza, como obrigação da família, da comunidade, da sociedade e do poder público, assegurar ao idoso, com absoluta prioridade, a efetivação do direito à vida, à saúde, à alimentação, à educação, à cultura, ao esporte, ao lazer, ao trabalho, à cidadania, à liberdade, à dignidade, ao respeito e à convivência familiar e comunitária (BRASIL, 2003).

Dentre os direitos protegidos nos diversos artigos do Estatuto do Idoso está o direito de prioridade na tramitação de processos, que deve ser observado nos procedimentos envolvendo pessoa idosa nos órgãos públicos e privados (BRASIL, 2003). O documento institui medidas de proteção gerais e específicas para a pessoa idosa e traz uma ampliação das leis já existentes, regulamentando os direitos assegurados às pessoas com idade igual ou superior a 60 anos, instituindo penas severas para quem desrespeitar ou abandonar os cidadãos nessa fase de curso da vida (BRASIL, 2003; CAMARANO; PASINATO, 2004; BATISTA; ALMEIDA; LANCMAN, 2011).

De acordo com o $\S 2^{\circ}$ do Artigo 71 do Estatuto do Idoso, a prioridade nos processos não cessa com a morte do beneficiário, mas se estende ao cônjuge sobrevivente, companheiro ou companheira com união estável, desde que possua mais de sessenta anos.

Assim, percebe-se que há, no Brasil, uma riqueza em leis especializadas para a garantia de direitos e proteção da pessoa idosa; porém, apesar de contar com uma legislação bastante avançada, o País ainda está despreparado para resolver as questões de cunho gerontológico, especialmente quando se referem aos direitos de igualdade de oportunidade e de tratamento em relação aos direitos e deveres da pessoa idosa.

Na verdade, pode-se dizer que, mesmo com toda essa proteção legal no sentido de construir uma nova visão de velhice, é comum a adoção de práticas discriminatórias, sem 
justificativa, contra a pessoa idosa (SERIBELI; AGUIAR, 2010). Ainda há muita intolerância arraigada, na forma de desrespeito aos mais velhos, dificultando ou impedindo o direito de acesso à justiça. Vale lembrar que a grande maioria dos seres envelhecentes no Estado do Piauí, assim como em muitas regiões do Brasil, vive em situação de pobreza e desconhece a força jurídica de seus direitos fundamentais.

Como afirma Bosi (1979), ao abordar o tema velhice em seu livro Memória e Sociedade: Lembrança de Velhos, a velhice, além de ser um destino do indivíduo, constitui-se numa categoria social, pois está em diferentes modos com que cada sociedade trata a pessoa idosa. E o que é ser velho na sociedade contemporânea e capitalista? Como conviver com as "velhices” diante das mais diversas mudanças, informações, tecnologias e benefícios científicos, em que, instantaneamente, tudo vai sendo transformado para o surgimento do novo, do moderno, do belo, do atual, gerando insegurança e alterações nas relações interpessoais?

Como bem diz Beck (1998), vive-se, hoje, numa sociedade de risco, moderna, reflexiva, líquida, em um mundo sem controle e sob a constante ameaça da insegurança e da incerteza, onde a sensação do medo e o enfraquecimento das relações humanas atingem a todos, diante da lógica de um tempo curto demais em um mundo complexo e globalizado (BAUMAN, 2004). Assim, as constantes mudanças decorrentes desses adventos, ocasionam, no direito, uma carga de impactos e transformações, seja porque os meios e os instrumentos utilizados pelo Judiciário são insuficientes e escassos, seja pela falta de visão do poder estatal de atuar ou, ainda, pela dinâmica da vida ritmada que assola o mundo líquido moderno.

Destarte, são inúmeras as dificuldades de superação do desafio de conciliar a complexidade das relações sociais marcadas pela dinâmica do tempo curto e do imediatismo com o tempo necessário para o desenvolvimento do processo, que nasce para demorar (racionalmente), evitando julgamentos imediatos, precipitações e arbitrariedades do Estado (LOPES JÚNIOR, 2003).

Enfim, quando se trata da questão da demora processual que clama por decisões que merecem novos contornos e envolve pessoas idosas como sujeitos processuais, há necessidade de um olhar específico, por parte do Estado e demais agentes processuais, tendo em vista a condição especial de fragilidade do idoso, que impõe o estabelecimento de direitos peculiares, como a prioridade na tramitação processual e a proteção integral por parte do Estado, da sociedade e da família.

Apesar do direito à razoável duração do processo estar garantido na Constituição Federal em vigor, sua efetivação ainda não está plenamente realizada. Concretamente, são muitas as causas 
envolvidas na demora da tramitação processual no Brasil, o que dificulta apontar onde está o verdadeiro gargalo dessa situação.

\section{O TEMPO DA PESSOA IDOSA NUMA PERSPECTIVA PROCESSUAL}

Assegurar que cada processo tenha uma vida própria e o seu desenvolvimento aconteça dentro de um tempo de duração razoável e com segurança constitucional é um importante desafio jurídico. A razoável duração do processo é uma garantia processual e corolário do devido processo legal, estando associada ao princípio do impulso oficial, segundo o qual "o processo civil começa por iniciativa da parte, mas se desenvolve por impulso oficial”, consoante disposto no Art. 262 do Código de Processo Civil (BRASIL, 2011).

No Brasil, por meio da Emenda Constitucional $n^{0} 45$, o direito à razoável duração do processo passou a ser expressamente previsto no ordenamento pátrio, com status de direito fundamental, previsto no Artigo 5, LXXVIII da CF, dispondo que "a todos, no âmbito judicial e administrativo, são assegurados a razoável duração do processo e os meios que garantam a celeridade de sua tramitação” (BRASIL, 2013).

A morosidade processual se torna mais grave quando a parte envolvida é pessoa idosa, seja pela sua fragilidade biológica, seja pelo desrespeito à sua garantia de prioridade, sendo que a violação desse direito afeta, de forma mais direta, a dignidade da pessoa humana. Nesse sentido, é importante lembrar o pensamento de Bobbio (1997), que soube expressar a influência que o tempo exerce na velhice. Sobre esse aspecto, preconiza o autor que o ritmo de vida fica cada vez mais lento na velhice, pois o tempo, como porvir, a cada dia fica mais curto, diferentemente do tempo do jovem, que segue adiante com o tempo mais longo em seu horizonte.

A concessão de tramitação prioritária para a pessoa idosa encontra seu fundamento de validade no rol dos direitos e garantias fundamentais, Artigo 5º LXXVIII, da Constituição Federal de 1988. A partir desse prisma e buscando aprimorar a prestação jurisdicional, o Estatuto do Idoso tem ainda operado em conjugação com a Emenda Constitucional $n^{0}$ 45/2004, a qual prevê um processo célere (BRASIL, 1988).

Sob o enfoque da celeridade processual, o Estatuto do Idoso alterou o Artigo 1.212 do Código de Processo Civil, determinando a redução da idade de 65 para 60 anos na prioridade de tramitação aos procedimentos judiciais em que figure, como parte, a pessoa idosa. Nesse sentido, surgiu a Lei $\mathrm{n}^{0}$ 12.008/2009, para adequar o texto do Código Civil às disposições normativas do 
Estatuto do Idoso, que, além de promover a redução da idade, incluiu o benefício da tramitação prioritária às pessoas portadoras de doenças graves (BRASIL, 2003a).

Ademais, a prioridade se estendeu aos processos e procedimentos administrativos que tramitam na Administração Pública, empresas prestadoras de serviços públicos, instituições financeiras e outras correlatas, assim como ao atendimento preferencial nas Defensorias Públicas referente aos Serviços de Assistência Judiciária (FONSECA, 2007).

Como se pode constatar, há um rol extenso de direitos constitucionais já afirmados e reforçados pelo Estatuto do Idoso. Diante disso, em relação às interfases presentes no processo de envelhecimento populacional, juntamente com o aumento da expectativa de vida no Brasil, percebese a necessidade de criar condições para que o prolongamento da vida se dê com qualidade. Isso requer o redimensionamento e a reestruturação do sistema de garantias dos direitos da pessoa idosa. A discussão sobre esses direitos positivados não garante, necessariamente, a sua efetivação, mas é um ponto de partida para que se consiga essa efetivação.

O que se extrai de tudo isso é o reconhecimento de que existe uma legislação ampla e atualizada, mas que não é aplicada, eficazmente, a serviço da pessoa idosa. Um dos motivos dessa inaplicabilidade talvez seja o desconhecimento, pelo próprio idoso e por grande parte da população, dos documentos legais. Além disso, há, em tais documentos, contradições, que também podem interferir na aplicação adequada da legislação.

O desafio é adotar medidas e procedimentos processuais num ritmo que atenda às necessidades prementes da pessoa idosa, garantindo-lhe o pleno usufruto de seus instrumentos legais ainda em vida. Nesse cenário complexo, as intervenções de urgências e provisórias surgem como verdadeiro milagre, tentando acompanhar o tempo da sociedade para conseguir alcançar a expectativa dos cidadãos, especialmente quando se verifica a presença do periculum in mora no processo, buscando a obtenção do resultado satisfatório em tempo hábil.

\section{A AÇÃo DE INTERDIÇÃo E O USO DE INSTRUMENTOS DE ACELERAÇÃo PARA A EFETIVIDADE DE DIREITOS}

No Brasil, a ação de interdição civil está prevista no Código de Processo Civil entre os procedimentos especiais de jurisdição voluntária, e os seus ritos estão contemplados nos artigos 1.177 a 1.186. Tais procedimentos processuais visam reconhecer a incapacidade em relação àqueles com mais de 18 anos que, apesar da idade, apresentam certa condição pessoal, seja devido à existência de enfermidade mental ou à ausência de discernimento, desde que essa condição impeça 
a pessoa de exercer com autonomia e independência seus direitos e obrigações na vida civil (VENOSA, 2011).

Ao ser deferida a prova da legitimidade do autor da interdição - pais ou tutores, cônjuge, qualquer parente ou, ainda, o Ministério Público (BRASIL, 2014, Artigo 1.177), bem como a prova da incapacidade do interditando para os atos da vida civil, a ação inicia-se com a petição inicial em juízo do domicílio da pessoa, apresentada por advogado ou defensor público (BRASIL, 2014, artigo 1.180), seguindo os mesmos requisitos do Art. 282, do Código de Processo Civil. Após essa etapa, o interditando será citado para, em dia e horário designados, comparecer perante o juiz para a audiência de interrogatório, com o objetivo de proporcionar ao magistrado elementos que, acrescidos de laudos e pareceres de especialistas, subsidiem a sua convicção e a prolação da sentença (MACHADO; FREITAS, 1981).

Nos casos em que não seja possível o comparecimento do interdito à audiência de interrogatório, o magistrado poderá substituir essa avaliação por uma inspeção judicial. O direito reconhece a necessidade de interdição quando da emissão de laudo por um perito da área médica, especificando a capacidade ou incapacidade e as técnicas empregadas para o resultado obtido, sendo, em seguida, deferido ou indeferido pelo juiz.

No prazo de cinco dias contados dessa audiência, o interditando poderá impugnar o pedido de interdição, sendo necessária a participação do Ministério Público. Decorrido esse prazo, é obrigatória a nomeação de um perito para aferir perícia médica ao interditando, sob pena de nulidade processual.

Todavia, é interessante mencionar os aspectos levantados por Carvalho (2014), com relação aos procedimentos e às exigências preconizadas nos artigos 1.181 e 1.183 do Código de Processo Civil (BRASIL, 2011). Os artigos determinam, respectivamente, a obrigatoriedade de citação do interditando para o interrogatório e a realização de perícia técnica para constatação da incapacidade. Entende esse autor que não há necessidade de a legislação obrigar a aplicação de tais artigos, já que existe a possibilidade de aplicação do princípio da equidade, em se tratando do instituto da interdição.

A equidade pode ser utilizada para encontrar o equilíbrio da norma com a situação de fato, promovendo a atenuação do rigor e da rigidez da lei (GAGLIANO; PAMPLONA FILHO, 2007). O princípio da equidade se justifica por estar, implicitamente, determinado nos princípios constitucionais e no Artigo $5^{\circ}$ da Lei de Introdução às Normas do Direito Brasileiro, segundo o qual, na aplicação da lei, o juiz atenderá aos fins sociais a que ela se dirige e às exigências do bem comum (DINIZ, 1996; CARLIN, 2004). 
O Artigo 127 do Código de Processo Civil (CPC) prevê que o juiz só pode julgar por equidade quando autorizado por lei; assim, nos procedimentos especiais de jurisdição voluntária (caso da ação de interdição), o juiz não é obrigado a seguir o excessivo rigor da formalidade da lei, conforme descrito no Artigo 1.109 do CPC (BRASIL, 2011). Portanto, o referido princípio somente pode ser utilizado em situações específicas, levando-se em conta as exigências do caso concreto e desde que a atenuação do rigor e da rigidez das leis seja acompanhada da garantia da segurança jurídica.

A ineficácia da justiça, quando a pessoa idosa é parte do processo, compromete, profundamente, a sua condição de subsistência e afeta sua vulnerabilidade, gerando perturbações que chegam a ser irreparáveis ou de difícil reparação, podendo, inclusive, impedir o aproveitamento do benefício, como acontece em casos de morte.

A antecipação de tutela é uma das principais formas de evitar os danos que o longo tempo de duração de um processo pode causar. De acordo com a Constituição Federal de 1988, a antecipação de tutela consiste num direito processual com status de direito fundamental, realizada por uma técnica de sumarização consistente em apreciar o feito antes da sentença, visando a minimizar os efeitos decorrentes da longa demora que o processo pode causar (BRASIL, 2011). Naturalmente, a pessoa idosa, pela sua condição especial de fragilidade, apresenta menor expectativa de sobrevida; portanto, é destinatária de direitos peculiares, tendo absoluta prioridade e proteção integral por parte do Estado, da sociedade e da família, como determina a Constituição Federal de 1988, o Código de Processo Civil e o Estatuto do Idoso.

É mister reafirmar que, dentro da conjuntura constitucional presente e diante dos desafios da pós-modernidade, a preocupação maior do direito atual deve ser com a pessoa humana. O direito não pode deixar de reconhecer a fraqueza e as limitações que certos grupos da sociedade apresentam, seja por fatores sociais, de sexo, de idade, de condição de saúde física ou mental, entre outros (MARQUES, 2014). Entre os grupos dos vulneráveis estão os idosos, e muitos deles não têm noção de que estão sendo vitimados por discriminação ou por desrespeito a seus direitos; aliás, eles muitas vezes não sabem sequer que são possuidores de direitos e de garantias constitucionais (SEGUIN, 2002).

Diante disso, torna-se necessário o empreendimento de ações sistemáticas e contínuas, visando orientar a população, em especial a própria pessoa idosa, como sendo merecedora de respeito e apoio necessários para a preservação e a conquista de diretos que propiciem o alcance de uma vida digna (MAFRA; GUIMARÃES, 2012). 
A dignidade da pessoa humana é o princípio norteador dos Estados constitucionais contemporâneos (BASTOS, 2011), positivada no Artigo 1º, Inciso III, da Constituição brasileira de 1988. Por ser um princípio supremo e, ao mesmo tempo, inerente à vida humana, deve ser plenamente respeitado em todas as relações jurídicas.

Nesse mesmo contexto, há que se registrar aqui a observação de Sarlet (2011), que consagra a dignidade humana como o direito ao reconhecimento, respeito, proteção e até mesmo promoção e desenvolvimento da dignidade, podendo inclusive falar-se de um direito a uma existência digna.

Cumpre salientar que essa dignidade apresenta dimensão dúplice na Constituição brasileira; ou seja, apresenta a função de direitos e de defesa, o que implica uma postura ativa do Estado em colocar à disposição dos indivíduos prestações de natureza jurídica e material. Para o autor, a dignidade é uma condição irrenunciável e pertencente a cada ser humano, por ser inafastável e inalienável (SARLET, 2011).

Apesar das dificuldades e complexidades decorrentes dos efeitos negativos da globalização econômica, enfraquecendo a capacidade do poder público de assegurar aos indivíduos a efetiva fruição dos direitos fundamentais, o Estado tem a tarefa de preservar a dignidade existente e possibilitar o pleno exercício da cidadania.

Logo, é preciso que a dogmática do sistema jurídico brasileiro seja guiada pela utilização dos direitos humanos, tendo como foco justamente a priorização da pessoa humana, em todas as suas dimensões, possibilidades, identidades e diferenças. Assim, sobre essa proteção, possa a pessoa idosa vislumbrar, no mundo globalizado, a garantia da aplicação desse novo direito, em busca da liberdade, da igualdade e da solidariedade.

Na proteção de direitos da pessoa idosa, percebe-se haver um estímulo à adaptação de leis orgânicas de modo a oferecer um melhor atendimento judicial e extrajudicial à defesa e à proteção dos idosos brasileiros. Nesse sentido, é evidente que a conquista, frente à prioridade na tramitação dos processos no âmbito do Poder Judiciário, é merecida e justa; porém, é preciso analisar se esse direito posto é efetivamente estabelecido para que o idoso brasileiro possa ser contemplado com todas as suas garantias constitucionais. 


\section{METODOLOGIA}

Trata-se de um estudo longitudinal, de caráter retrospectivo, utilizando-se pesquisa documental e bibliográfica, em relação à pessoa idosa assistida pela Defensoria Pública Estadual, no município de Teresina.

A pesquisa foi desenvolvida no Núcleo Especializado de Defesa e Atenção ao Idoso e da Pessoa com Deficiência da Defensoria Pública Estadual, em Teresina, Piauí, após esclarecimentos sobre os seus objetivos aos responsáveis pela Instituição, com vistas à autorização e emissão de Termo de Consentimento (Anuência), sendo garantido o sigilo e o anonimato das informações.

Após o consentimento e a autorização da pesquisa, foi realizado o levantamento dos processos, juntamente com estagiária, a partir de relatórios informativos do ano de 2013, elaborados, mensalmente, pelos defensores públicos. Os critérios utilizados para selecionar a amostra foram os processos de interdição judicial civil em que a pessoa idosa é parte, registrados, no ano de 2013, no Núcleo Especializado de Defesa e Atenção ao Idoso e da Pessoa com Deficiência da Defensoria Pública Estadual, em Teresina, PI.

Cada processo foi localizado, individualmente, no próprio site do Tribunal de Justiça, comarca de Teresina, pelo sistema ThemisWeb, e analisado pelo próprio pesquisador para permitir apreciar, cuidadosamente, as informações sobre o andamento dos processos. Verificaram-se sua movimentação e as decisões judiciais efetuadas em relação ao período compreendido entre a propositura da ação e a sentença, bem como as demais situações pertinentes a cada caso concreto.

Para calcular o tempo de duração dos processos, utilizou-se um modelo que permitiu identificar toda a cadeia processual, ou seja, o tempo decorrido entre a data de ajuizamento da ação, no ano de 2013, e o momento em que foi proferida a sentença de interdição ou a tutela provisória. Vale ressaltar que as consultas abrangeram os registros efetuados até 30 de setembro de 2014, data em que foi finalizada a pesquisa dos processos pelo ThemisWeb.

Os dados do presente estudo foram avaliados com o auxílio da estatística descritiva, como a média e a porcentagem, apresentando-se os resultados em forma de tabelas. E, com base nas referências teóricas levantadas, foram feitas as leituras e as interpretações para analisar, discutir e buscar explicações sobre os fenômenos investigados.

\section{RESULTADOS E DISCUSSÕES}

Nesta pesquisa foram identificados 77 processos com pedidos de interdição civil, ajuizados no ano de 2013 pela Defensoria Pública do Piauí; especificamente, pelo Núcleo Especializado de 
Defesa e Atenção ao Idoso e da Pessoa com Deficiência, em Teresina. Os processos atenderam aos critérios de inclusão descritos na metodologia. Esse cenário retrata uma média de, aproximadamente, sete ações mensais de interdição em que o idoso é parte, apontando para uma movimentação processual que requer uma demanda de cuidados especiais.

O aumento da expectativa de vida do brasileiro com mais de 60 anos aponta para o crescimento das demandas judiciais, o que exige reflexões e mudanças, especialmente no Poder Judiciário, para que se possa, efetivamente, assegurar o direito constitucional à razoável duração do processo e, consequentemente, garantir que o idoso possa ter o seu pedido atendido ainda em vida.

É importante salientar que os direitos da pessoa idosa deveriam ser uma questão importante ao interesse de todo cidadão brasileiro. Envelhecer é um processo natural, pessoal e irreversível, que acontece de forma contínua e inexorável no curso da vida. Dessa forma, o idoso deve também ter o direito de um envelhecimento saudável e acompanhado de merecido respeito (CARVALHO; MEDEIROS, 2003).

Assim, não há como deixar de perceber que o processo de envelhecimento diz respeito a toda a sociedade, que deve lutar para impedir que a pessoa idosa sofra qualquer forma de discriminação. Isso significa dizer que, para enfrentar os desafios trazidos pelo envelhecimento humano contemporâneo, é preciso compreender a realidade da pessoa idosa - notadamente, quando se percebe a necessidade da figura de um curador, diante da incapacidade do idoso de administrar seus bens e gerenciar sua própria vida.

Com efeito, o texto constitucional, em seu Artigo 5 , Inciso XXXV, garante o acesso à justiça e assegura ao idoso recorrer ao Poder Judiciário, na hipótese de qualquer lesão ou ameaça a seu direito (BRASIL, 2011). A exigibilidade desse direito não se restringe apenas ao texto normativo, é certo, que requer regras de direito material e a prestação jurisdicional do poder público na efetivação dos direitos decorrentes da ancianidade.

Como consequência disso, entende-se que o cidadão não tem simplesmente o direito à técnica processual evidenciada na lei, mas sim, direito a um determinado comportamento judicial que seja capaz de conformar a regra processual com as necessidades do direito material aplicado ao caso concreto (GONÇALVES-FILHO, 2010).

Em regra, toda pessoa, ao atingir a maioridade civil, passa a ter aptidão para, por si mesma, administrar sua vida e os seus bens, uma vez que, segundo o direito brasileiro, adquire a capacidade civil plena. Entretanto, há pessoas que, por motivo de doença ou debilidade mental, não conseguem mais expor suas vontades, cuidar de seus próprios interesses e de seus bens, estando, por isso, sujeitas à curatela. 
O Código Civil, em seu Artigo 1.767, menciona as hipóteses dos adultos incapazes que estão sujeitos à curatela, ou seja, aptos à interdição. São aqueles que, por enfermidade ou deficiência mental, não conseguem mais expor sua vontade, cuidar da sua vida e de seus bens, desde que decretada a prova da incapacidade (KUCHENBECCKER, 2013; BRASIL, 2014). Além das modalidades já conhecidas de interdição, total e parcial, o Código Civil de 2002 introduziu a possibilidade da curatela do enfermo ou portador de deficiência física, mediante disposição do Art. 1.768 (BRASIL, 2014).

Neste estudo, percebeu-se que as principais causas das demandas de interdição, envolvendo a pessoa idosa, são as doenças mentais severas, as sequelas de acidente vascular cerebral e a impossibilidade de locomoção. O sofrimento mental e a gravidade específica da situação, muitas vezes envolvendo múltiplas doenças, justificam a referida ação, que pode versar sobre a falta de discernimento, a total incapacidade física e a incapacidade mental do réu da ação.

Vale ressaltar que tais informações contradizem o afirmado pela juíza Ângela Gutierrez Gimenez, em entrevista veiculada pelo Tribunal de Justiça de Mato Grosso, Cuiabá, em que se destacou ser hábito bastante comum o pedido de interdição da pessoa idosa pautado apenas na faixa etária (acima de 70 anos) e não na sua situação mental (PINHEIRO; POLIPPO, 2014).

Sobre a perspectiva da idade, não se pode olvidar que a velhice, por si só, por mais avançada quer seja, não é admitida no ordenamento jurídico brasileiro como motivo para interdição, uma vez que não induz a incapacidade, salvo quando acompanhada de doenças mentais incapacitantes (ABREU, 2009; VENOSA, 2011).

Dentre os 77 processos de interdição identificados nos relatórios informativos mensais elaborados pelo Núcleo do Idoso no ano de 2013, foi possível consultar o andamento de 71 deles, a partir da consulta pública disponível no sistema ThemisWeb no site do Poder Judiciário do Piauí.

Percebeu-se que, em todos os processos, os requerentes eram filhas, filhos, esposo ou esposa, mãe ou pai, netos e, em um único caso, sobrinha ou prima. A idade dos interditados estava entre 60 e 100 anos, com mais de 50\% de idosos com mais de 70 anos. Houve apenas quatro casos de pedidos de interdição em que a parte ré não era pessoa idosa.

Constatou-se também que os grupos etários mais velhos são os mais envolvidos nos processos que buscam uma tutela de urgência. Ademais, denota-se, dessa realidade, uma situação de risco vivenciada pelos idosos, permeada pela doença grave e limitadora de gerenciamento de sua vida e de seus bens, pela condição de pobreza e/ou pela falta de conhecimento dos seus direitos, bem como pelas dificuldades que encontram para a obtenção do feito. 
Portanto, pode-se dizer que a vulnerabilidade é uma condição vivenciada pelos idosos desta pesquisa, já que ficam expostos a inúmeros fatores de ordem biológica, fisiológica, psicológica, social, econômica e estrutural. Além disso, o próprio Poder Judiciário também contribui com a imposição de dificuldades para este grupo social, seja pela morosidade processual, seja por conta de condutas de determinados juízes ao proferir decisões discricionárias.

De tudo isso, viu-se que a pessoa idosa se depara no cotidiano com o enfrentamento de situações adversas às suas necessidades de respostas urgentes, tendo que travar uma corrida contra o tempo, porque já estão no limite de subsistência.

Como bem diz Beck (1998, p. 19):

[...] a dimensão dos riscos que enfrentamos e os meios pelos quais tentamos lutar contra eles, a nível político e institucional, são tão deploráveis, que a fina capa de tranquilidade e normalidade é constantemente quebrada pela realidade bem dura de perigos e ameaças inevitáveis.

Torna-se, portanto, necessário tratar do problema com a devida urgência que o caso requer e buscar mecanismos hábeis e eficazes para evitar mais prejuízos à qualidade de vida da pessoa idosa a ser interditada. Não se pode deixar de reconhecer a fraqueza e as limitações que certos grupos da sociedade apresentam, seja por fatores sociais, de sexo, de idade, de condição de saúde física ou mental, entre outros (MARQUES, 2014).

Os dados referentes aos processos, nas suas diversas situações, estão descritos na Tabela 1. Ao analisar esses dados, observou-se que, dos 71 processos pesquisados, apenas 29 foram julgados entre janeiro de 2013 a setembro de 2014. Destes, 18 tiveram sentença com resolução de mérito, todas favoráveis à concessão da interdição e, consequentemente, o termo de curatela definitivo; quanto aos outros 11 processos, houve a extinção do feito sem resolução do mérito, por morte do interditando. Dos processos que possuíram sentença com resolução de mérito, 7 concederam a antecipação de tutela e, nos demais, a prolação da sentença foi diretamente deferida.

Dentre todos os processos analisados, em 24 deles o magistrado concedeu somente o pedido de antecipação de tutela, com a consequente expedição do termo de curatela provisório.

Tabela 1 - Distribuição dos processos, segundo o resultado do julgamento ou outra condição. Teresina, PI, 2014

\begin{tabular}{c|c|c|c|c|c}
\hline $\begin{array}{c}\text { Processos } \\
\text { julgados }\end{array}$ & Quant. & $\%$ & $\begin{array}{c}\text { Processos não } \\
\text { julgados }\end{array}$ & Quant. & $\%$ \\
\hline $\begin{array}{c}\text { Com resolução de } \\
\text { mérito }\end{array}$ & 18 & 25 & $\begin{array}{c}\text { Com antecipação de } \\
\text { tutela }\end{array}$ & 24 & 34 \\
\hline $\begin{array}{c}\text { Sem resolução de } \\
\text { mérito }\end{array}$ & 11 & 16 & $\begin{array}{c}\text { Sem antecipação de } \\
\text { tutela }\end{array}$ & 18 & 25 \\
\hline Total & 29 & 41 & Total & 42 & 59 \\
\hline
\end{tabular}


A constatação dos dados acima permite inferir que apenas $25 \%$ das ações de interdição atenderam, efetivamente, ao princípio constitucional da inafastabilidade da jurisdição, previsto no Art. 5º, inciso XXV da Constituição Federal de 1988, que dispõe que a lei não excluirá da apreciação do Poder Judiciário lesão ou ameaça a direito e que, sob uma ótica moderna, deve ser tido como o "oferecimento de um processo que efetivamente tutele o interesse da parte titular do direito material” (NEVES, 2014, p. 24).

Nesse sentido, apenas tal percentagem de processos atingiu o objetivo final da ação ora discutida; qual seja, a obtenção de uma sentença definitiva favorável, com a consequente expedição do termo de curatela definitivo, documento hábil a permitir que o autor da demanda cuide dos interesses do curatelado.

Por outro lado, aproximadamente $16 \%$ dos processos analisados não obtiveram êxito, tendo em vista que foram julgados extintos sem resolução do mérito, mediante sentença terminativa, por conta da morte da parte ré (pessoa idosa).

Ademais, há 42 processos, representando quase 60\% do total, que ainda estão em trâmite processual, uma vez que não foram julgados. Dessa quantidade, percebeu-se que em 24 deles (34\% dos processos), não obstante ainda não terem chegado ao fim, o magistrado da respectiva vara de família concedeu a antecipação dos efeitos da sentença, mediante o instituto da tutela antecipada.

Impende destacar que, em nenhum dos processos analisados, houve a improcedência do pedido.

Com efeito, a grande quantidade de deferimentos de antecipação de tutela chama atenção, especialmente quando se passa a analisar a fundamentação jurídica do magistrado mediante a leitura da decisão. Sabe-se que tutela antecipada é, em regra, uma medida de urgência, e, para a concessão do referido instituto, o juiz deve atender aos seguintes requisitos, dispostos no Art. 273 do Código de Processo Civil: a existência de prova inequívoca que o convença da verossimilhança das alegações, e que haja fundado receio de dano irreparável ou de difícil reparação.

Sobre a prova inequívoca, entende-se ser aquela à qual só é possível atribuir um sentido único, enquanto a verossimilhança da alegação significa que, apesar da prova inequívoca, a manifestação da parte deve parecer verdadeira, capaz de convencer o juiz quanto àquilo por ela invocado. Já o periculum in mora, ou seja, o perigo da demora, pode acarretar dano irreparável ou de difícil reparação. No entanto, analisando caso a caso, percebeu-se a existência de certa discricionariedade do magistrado na avaliação de tais critérios e na consequente concessão do instituto responsável pela antecipação dos efeitos da sentença. 
Por conta dessa discricionariedade, e até mesmo da arbitrariedade e do excesso de formalismo, a atuação de determinados juízes, no tocante à problemática apresentada na ação de interdição, acarreta alguns equívocos e atraso na prolação da sentença. Os fundamentos da decisão interlocutória concedente são vagos e genéricos, não havendo uniformidade em tais decisões.

Para melhor esclarecimento, colaciona-se trecho da decisão concedente do referido instituto pelo MM. Juiz da $5^{\text {a }}$ Vara de Família, em caso concreto em que a filha da idosa é autora da ação de interdição, cujo objetivo era obter a curatela da mãe, dependente de ventilação mecânica e internada na Unidade de Terapia Intensiva de um Hospital:

Assim, considerando o quadro criado em torno da saúde do(a) interditando(a), diante da documentação acostada aos autos, dentre elas o atestado médico colacionado aos autos afirmando que o interditando(a) encontra-se sem possibilidade de entendimento dos atos da vida civil, mister a concessão da medida liminar em antecipação de tutela.

Por sua vez, em outro caso em que o autor, idoso e irmão da parte ré, ajuizou ação de interdição em face da idosa, portadora da doença de Alzheimer, em junho de 2013, o MM. Juiz da $3^{\text {a }}$ Vara de Família e Sucessões, em sede de despacho, entendeu que deveria deixar para apreciar o pedido de curatela provisória somente após a audiência de interrogatório do interditando.

Ocorre que, assim como no caso anteriormente citado, o mesmo documento hábil a comprovar a condição incapacitante do réu era o atestado médico colacionado aos autos. No primeiro caso, foi considerado como sendo prova inequívoca da verossimilhança das alegações, mas, no segundo caso, não o foi assim considerado.

Esse tipo de discricionariedade foi encontrado em outros processos analisados, podendo-se concluir, ao final, que cada juiz, dependendo da vara e/ou do caso, concede, discricionariamente, a antecipação dos efeitos da sentença.

A partir da constatação de tais fatos, é impossível não se lembrar da história da Katchanga, de autoria do professor Luís Alberto Warat e narrada pelo jurista Lênio Streck (2013) como crítica à dogmática jurídica.

Segundo Streck (2013), a dogmática jurídica é um jogo de cartas marcadas, e a referida estória serve, justamente, para metaforizar e mostrar o paradoxo existente no sistema jurídico, que tem a pretensão de ser um sistema fechado quando, na verdade, deixa diversas lacunas passíveis de interpretação, especialmente pela magistratura, mediante decisões arbitrárias e discricionárias.

Os critérios encontrados na análise da decisão de concessão do instituto da tutela antecipada são os mesmos previstos no Art. 273 do CPC. No entanto, cada magistrado interpreta esse artigo de uma forma diferente. Uns consideram o atestado médico como documento hábil a 
demonstrar a verossimilhança das alegações, deferindo, desde logo, a antecipação da tutela. Por outro lado, outros desconsideram o atestado médico acostado aos autos, indeferindo, liminarmente, o pedido de antecipação de tutela, para, em seguida, designar audiência de interrogatório do interditando, a fim de, pessoalmente, atestar a incapacidade física ou mental do réu.

Resta claro pensar que o fato de alguns jurisdicionados conseguirem a concessão do instituto ora em discussão e outros não aconteça em decorrência do “decisionismo” tão criticado pelo eminente professor Lênio Streck, pois, em quase todas as ações de interdição, há um laudo médico acostado aos autos, sendo que, nos casos analisados, os interditandos idosos encontravamse, basicamente, na mesma situação. No entanto, apenas alguns possuem a “sorte” de ter o pleito apreciado por um magistrado que entenda ser possível a concessão.

Com efeito, a discricionariedade evidenciada nas práticas de magistrados no curso do processo de interdição, por sua vez, pode retardar o andamento do processo e prejudicar o interditando, bem como impedir o interessado - no caso, pessoa idosa - de ter seu direito tutelado tempestivamente, pois, na maioria das vezes, a solução chega tardiamente.

Dessa forma, não deve o juiz agir com discricionariedade, pois o que está em jogo são direitos constitucionais fundamentais, cuja garantia não pode ficar sujeita nem ser objeto de disposição arbitrária (ZAVASCKI, 1997).

Neste estudo, não foram incomuns os casos de extinção do processo sem resolução do mérito pelo falecimento da parte - pessoa idosa, a maioria com idade acima de 70 anos, apresentando graves problemas de saúde. Analisando tais processos, percebeu-se que a demora no andamento processual e na tomada de decisão do magistrado foi determinante para que os casos não fossem resolvidos antes do agravamento da situação do interditando.

Corroborando esse achado, o estudo de Carvalho, Gonçalves e Oliveira (2012) apontou que os processos em que a pessoa idosa figura como parte ou interessada continuam tendo um tratamento moroso e descuidado, fato que acaba gerando, na maioria dos casos, consequências graves.

A interdição é uma ação prioritária, intimamente ligada ao princípio da dignidade da pessoa humana. E, quando envolve pessoa idosa, a lei determina prioridade absoluta. A Constituição Federal exige a proteção integral às pessoas idosas e o Estatuto do Idoso, entre outras garantias, concedeu a prioridade na tramitação dos processos envolvendo pessoas com 60 anos de idade e mais, em virtude da sua condição natural de fragilidade, fato que não pode esperar a longa duração do processo (BRASIL, 1988; STEPANSKY; COSTA-FILHO; MULLER, 2013). 
No tocante à análise de duração da ação de interdição civil, observa-se, na Tabela 2, que a média foi de 189 dias para os julgados e de 159 dias para os que receberam tutela antecipada, o que corresponde a uma celeridade menor em relação aos que tiveram sentença.

Como se percebe na mesma tabela, a maioria dos processos julgados e que receberam a tutela antecipada ocorreu no prazo de até seis meses, contados da data de ajuizamento inicial até a data de prolação do feito, e até a data-limite de 30 de setembro de 2014, quando foi encerrada a investigação dos processos. O tempo médio foi de 189 dias para a sentença e de apenas 159 dias para os casos de tutela antecipada, o que parece indicar uma dificuldade para a prolação da sentença, talvez na expectativa de obtenção de elementos capazes de influir na decisão final.

Tabela 2 - Distribuição dos processos no tempo, segundo a prolação da sentença ou de tutela antecipada. Teresina, PI, 2014

\begin{tabular}{l|c|c}
\multicolumn{1}{c|}{ Tempo (meses) } & Sentença & Tutela Antecipada \\
\hline 1 a 6 meses & 19 & 15 \\
\hline 7 a 12 meses & 07 & 09 \\
\hline Mais de 12 meses & 03 & 0 \\
\hline Total & 29 & 24 \\
\hline Média em dias & 189 & 159 \\
\hline Média em meses & 6 & 5 \\
\hline
\end{tabular}

O tempo mínimo de duração para a obtenção do feito foi de 30 dias, enquanto o tempo máximo foi de 455 dias, sendo que o primeiro processo foi ajuizado em 09/01/2013 e o último em 19/12/2013. Lembrando que, para o cálculo da média, partiu-se da data da propositura da ação de interdição de cada processo e considerou-se até o dia 30 de setembro de 2014, período que se encerrou a avaliação dos processos no sistema ThemisWeb do site do Poder Judiciário do Piauí.

Estão ainda integrados nesse contexto os 18 processos que não obtiveram sentença e nem a antecipação de tutela, representando, aproximadamente, 25\% do total que ainda estão em trâmite, à espera de uma audiência de interrogatório ou de um laudo oficial de perícia médica ou social.

Assim, considerando que predomina a urgência nas ações de interdição e, por sua vez, segundo (BOBBIO 1997), o ritmo de vida fica cada vez mais lento na velhice, pois o tempo, como porvir, a cada dia fica mais curto, suscita grande preocupação a questão do tempo de duração de um processo judicial, especialmente nos casos envolvendo aqueles mais desprovidos de recursos financeiros. Por isso, é preciso assegurar a eficácia do provimento jurisdicional, para garantir à pessoa idosa a efetividade do acesso à justiça e dar cumprimento ao princípio da inafastabilidade do Poder Judiciário previsto na Constituição Brasileira (BRASIL, 1988).

As questões acerca da instrumentalidade e da efetividade processual vêm sendo bastante discutidas nas últimas décadas. Segundo Hoffman (2014), o processo adequado e justo deve 
demorar apenas o tempo necessário para a sua finalização, tendo-se sempre uma preocupação com a qualidade e buscando-se alcançar uma justiça rápida e efetiva. Dessa forma, percebe-se que não há um critério objetivo para a fixação de prazos visando determinar a razoabilidade do tempo processual, justamente por envolver casos concretos. No entanto, foram estabelecidos três critérios que devem ser analisados e seguidos: a complexidade do assunto, o comportamento das partes interessadas e a atuação dos órgãos jurisdicionais (BELO, 2010; MESQUITA, 2013).

Apesar disso, alguns magistrados, apegados a um formalismo exacerbado e à literalidade do disposto no caput do Artigo 273 do CPC, ainda não concedem a antecipação dos efeitos da tutela por entenderem que os requisitos da parte não satisfazem a concessão do feito (FONSECA, 2007).

Convém lembrar que o juiz não é obrigado a seguir o excessivo rigor da formalidade da lei, haja vista o princípio da equidade (Artigo 109 do CPP), que pode ser usado em situações em que se precisa buscar uma adaptação da norma ao caso concreto, levando-se em conta as especificidades que o caso exige e desde que a atenuação do rigor e da rigidez da lei não traga insegurança jurídica. O princípio da equidade se justifica pelo Artigo $5^{\circ}$ da Lei de Introdução às Normas do Direito Brasileiro, segundo o qual, na aplicação da lei, o juiz atenderá aos fins sociais a que ela se dirige e às exigências do bem comum (DINIZ, 1996).

Apesar de toda a dificuldade de se mensurar o tempo de duração razoável de um processo, esse direito é, constitucionalmente, garantido no ordenamento jurídico, ao dispor que "a todos, no âmbito judicial e administrativo, são assegurados a razoável duração do processo e os meios que garantam a celeridade de sua tramitação” (BRASIL, 2013; MESQUITA, 2013).

A espera por uma decisão que se delonga indefinidamente no tempo gera consequências graves e, muitas vezes, irremediáveis na vida daqueles que esperam por um tratamento diferenciado para a obtenção da efetiva prestação jurisdicional, até mesmo para aqueles que ainda são jovens. Na velhice, por inúmeras razões, os problemas são agravados por questões físicas, emocionais, psicológicas, econômicas e sociais, já que a pessoa idosa não possui a mesma resistência e vitalidade que as mais jovens (CARVALHO; GONÇALVES; OLIVEIRA, 2012).

De acordo com Lopes Júnior e Badaró (2009), o processo que corre em prazo não razoável deixa de assegurar três aspectos fundamentais: a) a dignidade da pessoa, que não pode ficar, indefinidamente, sofrendo as consequências que, por si só, um processo já provoca; b) o interesse probatório, na medida em que as provas se tornam mais frágeis com o passar do tempo; e c) a confiança na capacidade da justiça, já que, quando há atraso na prestação jurisdicional, a justiça perde, paulatinamente, a sua legitimidade. 
É evidente que é preciso também reconhecer que cada causa tem a sua especificidade, de modo que muitos fatores podem influenciar as decisões judiciais, favorecendo que o processo se alastre por muito tempo (CARVALHO; GONÇALVES; OLIVEIRA, 2012).

Nos processos em que a pessoa idosa é parte, o juiz deve, de ofício, determinar a tramitação preferencial. Daí em diante, o processo recebe uma marca de destaque para identificar a prioridade, para que os atos, em todas as fases, tenham preferência e tramitem mais rapidamente.

No presente estudo, observou-se que os processos recebem o carimbo de tramitação prioritária, uma forma de lembrar àqueles que atuam na tutela jurisdicional o envolvimento de um idoso no processo e que, por isso mesmo, devem ser agilizados os atos processuais em todas as suas fases. Cabe, portanto, registrar que a iniciativa é válida; porém, não basta colocar uma identificação na capa dos processos se o andamento deles, em toda a cadeia jurisdicional, não receber tratamento diferenciado.

Segundo Theodoro Júnior (2005), a simples existência de normas jurídicas prevendo a rapidez do processo não é suficiente, pois, muitas vezes, o problema está também nas pessoas envolvidas, que desconhecem ou desempenham suas atividades de forma burocrática e com excesso de formalismo, resultando em uma tramitação processual retardada e desnecessária.

Há evidências de que a garantia da duração razoável do processo está exatamente na sua aplicação, e não apenas na vigência da norma para o qual o princípio constitucional da razoável duração do processo tem a função integrativa de interpretar as regras procedimentais do Código de Processo Cível, conferindo corpo ao processo judicial ao lado do contraditório e da ampla defesa (MELO, 2010; SILVA, 2010).

Com efeito, a busca da verdade dos fatos não significa ficar o juiz, indefinidamente, perseguindo cegamente novas provas ou atuando numa posição acomodada, eternizando a duração do processo a todo custo. Quando se lida com a dignidade da pessoa humana, a mencionada tarefa deve ser realizada com diligência e cautela. Pretende-se, assim, envidar esforços para alcançar ao máximo a verdade substancial, mas de forma célere, para colaborar com a realização dos valores estampados no princípio da justiça no Estado Democrático de Direito (CÔRTES, 2006; MENDES, 2010).

A proteção jurídica da pessoa idosa encontra-se consagrada em diversos dispositivos legislativos, seja na Constituição Federal de 1988 ou no Código de Processo Civil, bem como no próprio Estatuto do Idoso, microssistema jurídico criado especialmente para tutelar os direitos daqueles que se encontram nessa fase da vida. No Artigo 71 do referido Estatuto há referência à prioridade na tramitação dos processos e procedimentos, bem como na execução dos atos e 
diligências judiciais em que figure, como parte ou interveniente, pessoa com idade igual ou superior a 60 anos (IOCOHAMA et al., 2007).

Na verdade, pode-se dizer que, apesar de toda essa proteção legal no sentido de construir uma nova visão de velhice, é comum a adoção de práticas discriminatórias, sem justificativa, contra a pessoa idosa. Ainda há muita intolerância arraigada, na forma de desrespeito aos mais velhos, dificultando o direito de acesso à justiça. Vale lembrar que a grande maioria dos seres envelhecentes no estado do Piauí, assim como em muitas regiões do Brasil, vive numa situação de pobreza, em que não se reconhece a força jurídica de seus direitos fundamentais.

Percebe-se, assim, que considerar a incapacidade da pessoa para todos os efeitos não é uma conjuntura simples, de fácil definição, embora cercada de aparatos legais. Existem diversos fatores envolvidos: a complexidade dos atos e dos casos apresentados, especialmente quando as partes apresentam idade avançada, os interesses de quem pede a interdição, além do volume de processos que tramitam nas unidades e dificultam a atenção que cada caso concreto merece (CARVALHO; GONÇALVES; OLIVEIRA, 2012; BRANDÃO, 2013).

O fato é que, em todos os processos analisados, os procedimentos adotados, na maioria das vezes, levaram muito tempo em tramitação para cumprir normas preestabelecidas ou buscar a verdade por meio dos exames médicos-periciais. Percebeu-se que, em quase todos os pedidos, o interditando tinha idade avançada (acima de 85 anos), bem como era portador de doenças graves, incluindo doença mental, e encontrava-se hospitalizado.

Todavia, é interessante refletir sobre os artigos que determinam a obrigatoriedade na realização de perícia técnica para constatação da incapacidade do interditando, já que existe a possibilidade de aplicação do princípio da equidade em procedimentos especiais, como é o caso do instituto da interdição (DINIZ, 1996; CARVALHO, 2014).

Com relação à proteção de direitos da pessoa idosa, percebe-se haver um entendimento voltado para garantir todas as oportunidades e facilidades que a lei determina, no sentido de oferecer um melhor atendimento jurídico na defesa dos direitos dos idosos brasileiros, para que possam usufruir deles ainda em vida.

É bem verdade que a maioria das pessoas idosas que litigam na Defensoria Pública do Piauí, no âmbito dos processos de interdição, está acometida por doença grave e, por isso, são merecedoras de tratamento diferenciado na aplicação da lei processual. Nesse diapasão, incidem inúmeros documentos legais. E, diante desse reconhecimento, entende-se que a Defensoria Pública, enquanto instituição essencial de assistência jurisdicional em favor dos hipossuficientes, tem como dever garantir a promoção dos direitos humanos e a proteção integral e gratuita em prol da 
população idosa, por meio de um acompanhamento em que prevaleça o princípio da dignidade da pessoa humana (MIRANDA; BANDEIRA, 2015).

No entanto, sabe-se que, para o efetivo acesso à Justiça, são muitos os fatores envolvidos que prejudicam os procedimentos de tramitação processual, destacando-se a exorbitante demanda processual, a ausência de uma adequada estrutura nos órgãos do Poder Judiciário, o excesso de burocracia e a ineficiência na solução dos conflitos, que maculam o princípio da razoável duração do processo, ao alongar demasiadamente o tempo necessário para obtenção do provimento jurisdicional, especialmente quando uma das partes está acometida por enfermidades graves.

Além dos aspectos já considerados, é oportuno registrar que, apesar dos avanços no sentido do reconhecimento dos direitos fundamentais como normas constitucionais, a crise vivenciada pelo Estado afeta não apenas a eficácia e a efetividade dessas normas, mas se revela também como uma crise na esfera do próprio reconhecimento e da identidade dos direitos fundamentais em um Estado Democrático de Direito (SARLET, 2011; 2014).

A dignidade da pessoa humana é o princípio de valor universal positivado no Artigo $1^{\circ}$, Inciso III, da Constituição brasileira de 1988. Por ser um princípio supremo e, ao mesmo tempo, inerente à vida humana, deve ser plenamente respeitado em todas as relações jurídicas. Logo, é preciso que a dogmática do sistema jurídico brasileiro seja guiada pela utilização dos direitos humanos, tendo como foco justamente a priorização do ser humano, em todas as suas dimensões, possibilidades, identidades e diferenças. Assim, sobre esta proteção, possa a pessoa idosa vislumbrar, no mundo globalizado e numa sociedade "líquida” de um tempo cada vez mais curto, a garantia da aplicação desse novo direito em busca da liberdade, da igualdade e da solidariedade.

\section{APORTES FINAIS}

De acordo com a pesquisa realizada, pode-se inferir que, dos 71 processos investigados em 2013, na Defensoria Pública do Estado do Piaú, no âmbito do Núcleo Especializado de Defesa e Atenção ao Idoso e da Pessoa com Deficiência, apenas 25\% das ações de interdição em que pessoa idosa é parte atenderam, efetivamente, ao princípio constitucional da inafastabilidade da jurisdição, com a consequente expedição do termo de curatela definitivo.

Ademais, tem-se que 59\% dos processos ajuizados ainda não foram julgados, sendo que, em apenas 34\% desses processos, o magistrado concedeu a antecipação dos efeitos da sentença, mediante o instituto da tutela antecipada. 
Não foram incomuns os casos de extinção do processo sem resolução do mérito pelo falecimento da parte - pessoa idosa, a maioria com idade avançada e apresentando graves problemas de saúde.

No tocante à análise de duração da ação de interdição civil, nos processos analisados os procedimentos adotados levaram, na maioria das vezes, muito tempo em tramitação para cumprir normas preestabelecidas ou para buscar a verdade por meio de exames médicos periciais.

De tudo isso, percebe-se que a pessoa idosa se depara, no cotidiano, com o enfrentamento de situações adversas às suas necessidades de respostas urgentes, tendo que travar uma corrida contra o tempo, porque já está no limite de subsistência, o que requer mudanças no Judiciário.

Torna-se necessário, portanto, tratar do problema com a devida urgência que o caso requer, e buscar mecanismos hábeis e eficazes a fim de evitar mais prejuízos à qualidade de vida da pessoa idosa a ser interditada.

Os dados relativos aos resultados dessa investigação trouxeram informações importantes que podem auxiliar a uma melhor compreensão do problema e a elucidar as práticas que dificultam a aplicação de direitos e garantias em relação à prioridade na tramitação de processos em ações de interdição em que pessoa idosa é parte.

As informações alcançadas sobre o tema poderão estimular outras pesquisas na área, visando à melhoria da qualidade de vida da população pesquisada e, ainda, poderão estimular as pessoas idosas a lutarem por seus direitos.

\section{REFERÊNCIAS}

ARRUDA, S. M. O direito fundamental à razoável duração do processo. Brasília: Brasília Jurídica, 2006.

ABREU, C. B. Curatela e Interdição Civil. Rio de Janeiro: Lumen Juris, 2009.

BANCO MUNDIAL. Envelhecendo em um país mais velho. Implicações do envelhecimento populacional para o crescimento econômico, a redução da pobreza, as finanças públicas e a prestação de serviços. Washington: The World Bank, 2011.

BASTOS, M. dos S. Da Inclusão das Minorias e dos Grupos Vulneráveis: Uma Vertente Eficaz e Necessária Para a Continuidade da Ordem Jurídica Constitucional. Revista Brasileira de Direito Constitucional, n. 18, jul./dez, 2011.

BAUMAN, Z. Amor líquido. Rio de Janeiro: Jorge Zahar, 2004.

BECK, U. La sociedad del riesgo. Hacia una nueva modernidad. Madrid: Paidós, 1998. 
BELO, D. P. A razoável duração do processo como instrumento de acesso à justiça. Revista Direito e Desenvolvimento, João Pessoa, v. 1, n. 2, p. 55-68, jul/dez, 2010.

BOBBIO, N. O tempo da memória. De senectude e outros escritos autobiográficos. Rio de Janeiro: Campus. 1997.

BRANDÃO, S. V. Interdição Civil Solicitada por Familiar em Face de Parente Idoso: Desconstrução da Autonomia Privada ou Construção de um Cuidado? 2013. 25 f. Monografia de Conclusão de Curso (Especialização em Educação em Saúde Mental Coletiva) - Universidade Federal do Rio Grande do Sul, Porto Alegre, 2013.

BRASIL. Constituição (1988). Constituição da República Federativa do Brasil: promulgada em 5 de outubro de 1988. Brasília, DF: Senado Federal, 1988.

. Lei n. 8.842, de 4 de janeiro de 1994. Dispõe sobe a Política Nacional do Idoso e dá outras providências. Diário Oficial da União: República Federativa do Brasil: Poder Legislativo, Brasília, DF, 5 janeiro 1994. Disponível em: <http://goo.gl/2bbkmZ>. Acesso em: 10 set. 2014.

Lei n. 10.741 , de $1^{\circ}$ de outubro de 2003. Dispõe sobre o Estatuto do Idoso e dá outras providências. Diário Oficial da União: Seção I, 3 outubro 2003a. Disponível em: $<$ http://goo.gl/RNs5RH>. Acesso em: 10 set. 2014.

. Plano de Ação Internacional para o Envelhecimento Humano. Organização das Nações Unidas. Brasília: Secretaria Especial dos Direitos Humanos, 2003b.

Constituição da República Federativa do Brasil: promulgada em 5 de outubro de 1988. Organização do texto por Yussef Said Cahali. 13. ed. São Paulo: Editora Revista dos Tribunais, 2011. 2046 p. (Mini Códigos).

. Lei Complementar n. 80 de 12 de jan. de 1994. Organiza a Defensoria Pública da União, do Distrito Federal e dos Territórios e prescreve normas gerais para sua organização nos Estados, e dá outras providências. Diário Oficial da União: Seção I, 13 janeiro 1994. Disponível em: <http://goo.gl/Nj5GA>. Acesso em: 14 mai. 2013.

CARVAlHO, C. M. R. G.; MEDEIROS, H. C. Guia da Pessoa Idosa: Legislação e Serviços. Teresina: Editora Gráfica Expansão, 2003. 362 p.

CARVALHO, J. de; GONÇALVES, W. F.; OLIVEIRA, S. A. de. A morosidade da justiça brasileira nos julgamentos dos processos de pessoas idosas. Revista do Instituto do Direito Brasileiro, ano I, n. 3, p. 12-57-1294, 2012.

CARVALHO, N. Citação do interditando e pericia são desnecessárias. Dom total Direito, 2012. Disponível em: <http://goo.gl/IwR6gV>. Acesso em: 22 nov. 2014.

CARLIN, M. O Julgamento por Equidade nos Juizados Especiais Cíveis: uma abordagem à luz da convergência entre os Sistemas Jurídicos da Civil Law e da Common Law e do movimento contemporâneo de acesso à Justiça. 2004. 169 f. Dissertação (Mestrado em Ciência Jurídica) Curso de Pós-Graduação Stricto Sensu em Ciência Jurídica, Universidade do Vale do Itajaí, Itajaí, p. 127, 2004. 
CÔRTES, O. M. P. O acesso à justiça e a efetividade da prestação jurisdicional - o inciso LXXVIII do art. $5^{\circ}$ da Constituição Federal inserido pela EC 45/2005. Revista de Processo, São Paulo, a. 31, n. 139, p. 79-91, ago. 2006.

DINIZ, M. H. Lei de introdução ao código civil brasileiro interpretada. 2. ed., atual. e aum. São Paulo: Saraiva, 1996.

FOUCAULT, M. A Verdade e as Formas Jurídicas. Rio de Janeiro: Nau, 1998.

FONSECA, S. F. S. A concessão da tutela antecipada em face de sua postulação implícita. 2007. 100 f. Dissertação (Mestrado em Direito) - Universidade Católica de Pernambuco, Recife, 2007.

GAGLIANO, P. S.; PAMPLONA FILHO, R. Novo curso de direito civil, volume I: parte geral. 9. ed. rev. atual. e ampl. São Paulo: Saraiva, 2007, p. 22 et seq.

GONÇALVES-FILHO, J. G. O Principio Constitucional da Eficiência no Processo Civil. 2004. 455 f. Doutorado (Tese Faculdade de Direito da USP) - Universidade de São Paulo, São Paulo.

HOFFMANN, P. O direito à razoável duração do processo e a experiência italiana. Disponível em: <http://jus2.uol.com.br/doutrina/texto.asp?id=7179>. Acesso em: 18 out. 2014.

IBGE. Instituto Brasileiro de Geografia e Estatística. Contas Nacionais - Conta-Satélite de Saúde 2007-2009. Rio de Janeiro: IBGE, 2012.

IOCOHAMA, C. H. et al. A Preferência de Tramitação para os Processos de Idosos. Revista Ciência Jurídica e Sociedade, Unipar, v. 10, n. 1, jan./jun., 2007.

KUCHENBECKER, R. T. Direito do idoso da Capacidade à Interdição. 2013. 47 f. Trabalho de Conclusão de Curso (Graduação em Direito) - Universidade Tuiuti do Paraná, Curitiba, 2013.

LOPES JÚNIOR, A. Processo penal, tempo e risco: quando a urgência atropela as garantias. In: BONATO, Gilson (Org.). Processo penal: leituras constitucionais. Rio de Janeiro, 2003.

; BADARÓ, G. H. Direito ao Processo Penal no Prazo Razoável. 2 ed. Rio de Janeiro: Lumen Juris, 2009.

MACHADO, J. A. de A.; FREITAS, G. P. Interdição e curatela. 2. ed. Bauru/SP: Editora Jalovi, 1981.

MAFRA, A. L. S.; GUIMARÃES, J. dos R. Conhecimento dos idosos sobre seus direitos garantidos no Estatuto do Idoso - Estudo Comparativo entre Idosos Institucionalizados e Não Institucionalizados. Revista Funec Científica Multidisciplinar, Santa Fé do Sul (SP), v. 2, n. 3, jul./dez. 2012.

MARQUES, C. L. Algumas Observações sobre a Pessoa no Mercado e a Proteção dos Vulneráveis no Direito Privado Brasileiro. In: GRUNDMANN, S.; MENDES G.; MARQUES, C. L.; BALDUS, C.; MALHEIROS, M. Direito Privado, Constituição e Fronteiras. 2a . ed., revista, atualizada e ampliada. São Paulo: Editora Revista dos Tribunais, 2014. 
MESQUITA, I. da S. A garantia fundamental à razoável duração do processo e a celeridade de tramitação na Constituição Federal: a construção de parâmetros. In: IOCOHAMA, C. H; SALDANHA, J. M. L (Coord.). Processo e Jurisdição (Recurso eletrônico on-line). CONDEPI UUNICURITIBA (Org.). Florianópolis: FUNJAB, 2013. p. 286-315. Disponível em: <http://www.publicadireito.com.br/publicacao/unicuritiba/>. Acesso em: 26 ago. 2014.

MELO, J. P. dos S. Duração razoável do processo. Porto Alegre: Sérgio Antonio Fabris, 2010.

MENDES, G. F.; COELHO, I. M.; BRANCO, P. G. G. Curso de Direito Constitucional. $4^{\mathrm{a}}$ ed. São Paulo: Saraiva, 2010.

MIRANDA, A. T. P. de; BANDEIRA, M. V. B. Paciente judiciário: o esforço coletivo na quebra de paradigma. Revista Jurídica da Defensoria Pública da Bahia, v.2, p. 9-21, 2015.

NEVES, D. A. A. Manual de direito processual civil. 6a. ed. rev., atual. e ampl. Rio de Janeiro: Forense; São Paulo: Método, 2014.

PINHEIRO, J.; POLIPPO, J. Quando os pais viram filhos e é preciso interditar. Tribunal de Justiça do Mato Grosso Cuiabá (MT). Coordenadoria de Comunicação do TJMT. Disponível em: <http://goo.gl/g9ZZui>. Acesso em: 22 out. 2014.

SÉGUIN, E. E. Minorias e Grupos Vulneráveis: Uma abordagem Jurídica. Rio de Janeiro: Forense, 2002, p. 12.

SERIBELI, N. H.; AGUIAR, T. M. S. O Idoso em Situação de Abandono: Demanda para o Serviço Social no Âmbito do Ministério Público do Estado de São Paulo. Seminário Integrado, v. 4, p. 88115, 2010.

SILVA, E. O. Duração razoável do processo. Universidade Anhanguera - Uniderp, Rede de Ensino Luiz Flávio Gomes, 2010. 50 f. (Monografia) Pós-Graduação em Direito Processual Civil.

SILVA, C. R. Equidade nas decisões judiciais: hipóteses de cumprimento pelo Estado de sua função social. Revista da Esmesc, Santa Catarina, v. 20, n. 26, 2013.

STEPANSKY, D. V.; COSTA-FILHO, W. M. da C.; MULLER, N. P. (Org.). Estatuto do Idoso. Dignidade Humana como Foco. In: PINHEIRO, N. M.; NOBREGA, A. M. P. de. Atendimento Prioritário ao Idoso. Brasília: Secretaria de Direitos Humanos, 2013, Parte II. p. 102-111.

SARLET, I. W. Dignidade da pessoa humana e direitos fundamentais na Constituição Federal de 1988. 9. ed. rev. atual. Porto Alegre: Livraria do Advogado, 2011.

. A Eficácia dos Direitos Fundamentais - Uma Teoria Geral dos Direitos Fundamentais na Perspectiva Constitucional. 12. ed., Porto Alegre: Livraria do Advogado, 512 p., 2014.

STRECK, L. L. Compreender direito: desvelando as obviedades do discurso jurídico. São Paulo: Editora Revista dos Tribunais, 2013. 
THEODORO JÚNIOR, H. Celeridade e efetividade da prestação jurisdicional. Insuficiência da reforma das leis processuais. Revista de Processo. São Paulo: Revista dos Tribunais, a. 30, n. 125, p. 61-78, jul. 2005.

VENOSA, S. de S. Código Civil Interpretado. 2. ed. São Paulo: Atlas, 2011.

ZAVASCKI, T. A. Antecipação da tutela. São Paulo: Saraiva, 1997.

\title{
THE STRUGGLE FOR THE REALIZATION OF THE RIGHT: ANALYSIS OF THE PROCEDURE FOR ELDERLY IN THE PIAUÍ STATE PUBLIC DEFENDER'S OFFICE
}

\begin{abstract}
The delay in service for the elderly can bring serious consequences and it has been linked to discriminatory and prejudiced practices. The insanity proceeding is a theme of public interest because it is a mechanism to support and protect the interdict. The objective of this research is to analyze the guarantee of protection of the right to procedural priority in insanity proceedings involving elderly people. This study, based on documents and bibliographic sources, made use of lawsuits of civil interdiction regarding actions filed in 2013 by the Specialized Center for Defense and Care for Elderly and Disabled People of the Piauí State Public Defender's Office. From the 71 cases examined, only $25 \%$ of the insanity proceedings had the expedition of the definitive term of curatorship; 59\% have not yet been judged, and, from these, only 34\% had the preliminary injunction grant. Many elderly died before a judicial solution. The procedures adopted for the insanity proceeding, in most cases, have taken too long time. The biological and social vulnerability is a condition lived by the elderly researched, besides a set of difficulties imposed by the judiciary. It is expected that the results of this research will help to better understand the problem and bring intervention models, as legal proposals that contribute to meet the needs of the elderly while they are still alive. The information collected about the subject may stimulate other researches in the area aiming at the improvement in life quality of the studied population.
\end{abstract}

KEYWORDS: Access to justice. Insanity proceeding. Old age. 